\title{
Substance Use, Mental Health, and Weight-Related Behaviors During the COVID-19 Pandemic Among Metabolic and Bariatric Surgery Patients
}

\author{
Sarah E. Messiah ${ }^{1,2}$ (1) $\cdot$ Maduri Uppuluri ${ }^{1,2} \cdot$ Luyu Xie $^{1,2} \cdot$ Jeffrey N. Schellinger ${ }^{3} \cdot$ M. Sunil Mathew ${ }^{1,2} \cdot$ Ashley Ofori $^{1,2}$. $^{1}$ \\ Sachin Kukreja ${ }^{4}$ - Benjamin Schneider ${ }^{5}$ Samuel H. Dunn ${ }^{5}$ - Anna Tavakkoli ${ }^{5}$ - Jaime P. Almandoz ${ }^{1}$
}

Received: 19 February 2021 / Revised: 13 May 2021 / Accepted: 14 May 2021 / Published online: 27 May 2021

(C) The Author(s), under exclusive licence to Springer Science+Business Media, LLC, part of Springer Nature 2021

\begin{abstract}
Purpose The impact of the COVID-19 pandemic on behavioral issues among those who have completed bariatric surgery (BS) is not well described in ethnically diverse populations. The aim of this study was to compare the impact of COVID-19 lockdown orders and after lockdown orders were lifted on substance use, mental health, and weight-related behaviors among a sample of post-BS adults.

Materials and Methods A retrospective medical chart review identified BS patients from one university-based obesity medicine clinic and two BS practices. An online non-anonymous survey was implemented in two phases: during lockdown (April 1-May 31,2020 ) and after lockdown orders were lifted (June 1, 2020-September 30,2020) to obtain information about the COVID-19 pandemic's impact on BS patients.

Results A total of 189 (during lockdown=39, post-lockdown=150) participants $(90.4 \%$ female, mean age 52.4 years, SD 11.1, 49.8\% non-Hispanic White, 30.6\% non-Hispanic Black, 16.1\% Hispanic) participated. Lockdown participants were more likely to have sleep problems $(74.3 \%$ vs. $56.1 \%, \mathrm{P}=.039)$ and feel anxious $(82.0 \%$ vs. $63.0 \%$, $\mathrm{P}=.024)$ versus post-lockdown participants. A majority (83.4\%) reported depression in both lockdown/post-lockdown. Post-lockdown participants were more than 20 times more likely to report substance use compared those in lockdown (aOR 20.56, 95\% CI 2.66-158.4).
\end{abstract}

All authors are affiliated: Paul M. Bass Administrative and Clinical Center, 6363 Forest Park Road, BL10.204, Dallas, TX 75390, USA.

\section{Key Points}

The COVID-19 pandemic has resulted in durable health impacts for BS patients.

Substance use significantly increased over the course of the pandemic in BS patients.

High levels of insomnia, anxiety, and depression were self-reported in ethnically diverse BS patients.

There may be a bidirectional relationship with these health challenges in BS patients.

All authors are affiliated: Paul M. Bass Administrative and Clinical Center, 6363 Forest Park Road, BL10.204, Dallas, TX 75390, USA

\section{Sarah E. Messiah}

Sarah.E.Messiah@uth.tmc.edu;

Sarah.Messiah@utsouthwestern.edu

School of Public Health, University of Texas Health Science Center, Dallas, TX, USA

2 Center for Pediatric Population Health, Children's Health System of Texas and UT Health School of Public Health, Dallas, TX, USA

3 Division of Endocrinology, Department of Internal Medicine, University of Texas Southwestern Medical Center, Dallas, TX, USA

4 Minimally Invasive Surgical Associates, Dallas, TX, USA

5 Department of Surgery, University of Texas Southwestern Medical Center, Dallas, TX, USA 
Conclusions and Relevance The COVID-19 pandemic is having a substantial negative impact on substance use, mental health, and weight-related health behaviors in diverse BS patients. These findings have important implications for post-BS patient care teams and may suggest the integration of screening tools to identify those at high risk for behavioral health issues.

Keywords Bariatric surgery $\cdot$ COVID-19 $\cdot$ Behaviors $\cdot$ Mental health $\cdot$ Substance use

\section{Introduction}

The severe acute respiratory syndrome coronavirus 2 (SARSCoV-2) outbreak reached the epidemiological definition of a global pandemic in March 2020, which placed substantial stress on healthcare systems throughout the world and resulted in governments issuing lockdown and stay-at home orders [1]. SARS-CoV-2 causes coronavirus disease 2019 (COVID-19), which has been shown to cause more severe disease in people with obesity [2-9].

Furthermore, some studies show that bariatric surgery (BS), a safe and effective procedure to treat obesity and its comorbidities [10-15], may be protective against severe COVID-19 with decreases in hospitalization, intensive care requirements, and mortality [16-18]. Elective surgeries, including BS, were canceled during the pandemic to preserve hospital capacity for the excess of critically ill patients associated with the pandemic [19]. Stay-at-home mandates have also disrupted the dietary and physical activity habits of many people with obesity resulting in increased difficulty in attaining weight loss goals, reduced physical activity, and increases in stockpiling food [20]. In post-BS patients, there is a report of patients in Brazil who struggled with protein intake and managing processed food consumption; however, weightrelated behaviors during the COVID-19 pandemic have not yet been fully characterized for post-BS patients in the USA through 2020 [21].

Several systematic reviews have shown that in the general population, the COVID-19 pandemic is strongly associated with poor mental health outcomes [22-24]. Other reviews have documented the deleterious impact of the epidemic among those living with mental illness [25-27]. In addition to weight-related behaviors, there are psychosocial challenges for BS patients during the COVID-19 pandemic as well, including increased substance and alcohol misuse [28-30]. Indeed, several studies have reported lifetime psychiatric illness in MBS patient populations with rates as high as $50-70 \%$ [31-33]. Social orders that enforce distancing and isolation for BS patents who are at greater risk for mental health issues have exacerbated these documented underlying psychiatric disorders [34, 35]. A US single-site study conducted early in the epidemic among 208 BS patients showed 44\% of participants reported increased depression, as well as loneliness (36.2\%), nervousness $(54.7 \%)$, snacking $(62.6 \%)$, loss of control eating (48.2\%), binge eating (19.5\%) and decreases in their social support $(23.2 \%)$, healthy eating $(45.5 \%)$, and physical activity $(55.2 \%)$. Patients more than 18 months postBS regained more than $2 \mathrm{~kg}$ over an average of 47 days. Risk factors for weight regain included loss of control eating, increased snacking and binge eating, reduced consumption of healthy foods, and reduced physical activity [36]. A similar study in Poland found that patients both pre- and post-BS reported weight gain during April 2020 [37]. In Brazil, one study showed that almost $90 \%$ of postbariatric patients were not consuming enough protein and that almost a quarter of their diet consisted of ultraprocessed foods, [38] while another study from Brazil reported that adherence to social distancing orders significantly increased sedentary behaviors and decreased time spent in moderate to vigorous physical activities [39]. Among 434 BS subjects in Italy, who were either waiting for BS or who had completed it, $37 \%$ and $56 \%$ felt lonelier and more bored, respectively, $66 \%$ were hungrier with increased frequency of snacking (55\%), 39\% reported more impulse to eat, and $49 \%$ reported they were unable to follow a recommended diet [40]. While survey studies in adults across the USA and Europe have shown that alcohol consumption has increased during the SARS-CoV-2 pandemic, little is known about the pandemic's effect on substance abuse in patients with prior BS [41-45].

Given the paucity of information on the pandemic's effect on BS patients, especially those from ethnically diverse backgrounds, this study aimed to assess the effect of the SARSCoV-2 social distancing measures on patients with prior BS surgery in three key areas: (1) substance abuse, (2) mental health, and (3) weight-related behaviors. It was hypothesized that the SARS-CoV-2 pandemic has had a substantial negative impact on this patient population. A secondary goal was to compare the impact of the COVID-19 pandemic during two distinct time periods: (1) during lockdown orders (MarchMay 2020) and (2) after lockdown orders were lifted (JuneSeptember 2020) to assess if there was any reported impact over the second period of time in particular.

\section{Methods}

Design A retrospective chart review identified patients who completed BS from an academic healthcare system's obesity 
medicine clinic, BS clinic, and a community-based BS practice. Clinic staff then sent an invitation via email to potential participants that included a short description of study involvement that included completing an online questionnaire.

Procedure An online non-anonymous survey was implemented in two phases: during lockdown orders from April 1 to May 31, 2020, and post-lockdown orders from June 1, 2020, to September 30, 2020, to obtain information about the COVID-19 pandemic's impact on patients who completed BS. State-mandated lockdown orders lasted about 5 weeks (March 31-May 5, 2020), and the study post-lockdown measures started approximately 4 weeks after lockdown orders were lifted (June 5, 2020) and was implemented through September 30, 2020 (or for about 4 months). During both phases, BS patients were asked to respond to a survey about the COVID-19 pandemic's effect on their health and lifestyle behaviors. The lockdown phase questionnaire consisted of 85 questions and post-lockdown questionnaire consisted of 147 questions (see Supplemental Files for each complete survey). Participants signed an online consent and authorized contact for follow-up information. Study data were collected and managed using Research Electronic Data Capture (REDCap) $[46,47]$ electronic data capture tools hosted at the academic institution. The University of Texas Health Science Center Institutional Review Board approved the study.

Study Location and COVID-19 Infections This study took place in Dallas-Fort Worth, the fourth largest metro areas in the USA with a population of over 7.5 million [48]. Local health department data approximated 9173 COVID-19 infections in the metroplex as of May 5, 2020 (when lockdown orders ended) and 171,620 cases as of September 30, 2020 (when data collection for this study ended) [49].

Measures Participants were queried on a variety of areas including demographics and the impact of the COVID-19 pandemic on their lifestyle behaviors, substance use, and physical and mental health. To help ensure validity, wherever possible, all questionnaire headers, questions, and response formats were adapted from standardized instruments available through the PhenX [50] toolkit and the Behavioral Risk Factor Surveillance System (BRFSS) questionnaires [51]. The primary dependent variable of interest was substance use $(\mathrm{Y} / \mathrm{N})$, and primary independent variables were weightrelated behaviors and psychological factors, such as anxiety and depression. Covariates include age, gender, education, BMI, and COVID-19 infection.

Demographics Demographic questions were based on the validated BRFSS instrument [51]. Respondents were asked about their gender, race/ethnicity, age, marital status, education level, basic anthropometrics (height/weight), and household income.
Employment The survey assessed changes in employment, including job loss and decrease in working hours. Essential worker designation was also determined and if they were working remotely.

COVID-19 COVID-19-related questions focused on infection of the subject or family members with the virus, history of testing, difficulty getting tested, or COVID-19 symptoms. All participants were asked about existing chronic medical conditions, which would put them at greater risk for more severe COVID19 complications.

Lifestyle Behaviors Survey respondents were asked about the frequency that they were leaving the house and social activities, which ranged from staying completely isolated at home to attending large social gatherings. A variety of Likert scale questions required respondents to compare their lifestyle behaviors before and since the COVID-19 pandemic (How often do you go out to the grocery store to shop for food?) (Do you stockpile food due to COVID-19?). Questions related to their health included changes to exercise, healthy habits, and the quality and quantity of food consumption (Has it been more challenging to stick with your healthy eating pattern due to the available food options in your local grocery store?) (Since COVID-19, has your consumption of the following foods (fast foods, fresh fruits, pizza, processed meats, red meat, restaurant foods, snacks/potato chips, soda/sugar sweetened beverages, vegetables) changed?) (Do you cook more or less due to COVID-19?) (Do you bake more or less due to COVID19?) (Have you increased ordering restaurant to-go/delivery foods to avoid going to the grocery store?). Additionally, food security was evaluated using the validated 6-item US Adult Food Security Survey Module [52].

Depression Depressive symptoms were assessed in survey respondents with the validated 16-item Quick Inventory of Depressive Symptomatology (QIDS-SR ${ }_{16}$ ) [53]. Participants were queried on variety of elements, such as sleep, appetite, and anxiety, and how these had changed over the prior 7 days. The QIDS-SR 16 has been vetted against several other dimensional measures for depression and was ultimately selected for this study because it is free, easily administered as a selfreported instrument for ages 12 and above, and captures the general symptoms of depression.

Anxiety Depression commonly co-occurs with clinically significant levels of anxiety [54]. Thus, anxiety was measured via the following QIDS-SR 16 question: "I do not feel anxious," "I feel anxious less than half the time," "I feel anxious more than half the time," "I feel anxious nearly all of the time."

Substance Use Substance use behavior was assessed by National Epidemiologic Survey on Alcohol and Related 
Conditions (NESARC) [55]. As per NESARC's standardized protocol, current alcohol use is defined as any use of alcohol in the past 30 days. Participants reporting use of any illicit drugs, having any alcoholic beverages during the past 30 days, or current cigarette smoking were categorized as substance users and composed of $26.9 \%(\mathrm{~N}=51)$ of the sample. Others were categorized as non-users. To assess the change of these behaviors due to the pandemic, we asked the participants to report if they increased the use of any recreational substances, including alcohol and tobacco, since the COVID-19 stay-athome orders were issued.

\section{Statistical Analysis}

Descriptive analysis was performed for baseline characteristics including age, sex, race/ethnicity (non-Hispanic White (NHW), non-Hispanic Black (NHB), Hispanic, and other), education, annual household income, time since surgery, body mass index (BMI), and chronic medical conditions and as well as COVID-19 related information including test results (positive/negative), symptoms (yes/no) and level of quarantine (from not going outside at all to going out as normal). Detailed information on substance use, including illicit drug use, was also reported. Pearson chi-square tests compared the change of weight-related behaviors and psychological factors including food stockpiling, stress eating, difficulty falling asleep, anxiety, depression, and substance abuse, in lockdown versus post-lockdown. Crude and adjusted odds ratios were calculated for BS participants in post-lockdown compared to lockdown participants to determine the odds of increased substance use, anxiety, depression, and weight-related behaviors as the primary/dependent outcomes. Adjusted logistic regression models were controlled for age, gender, race/ethnicity, education, BMI, prior BS (Y/N), and COVID-19 infection. We also explored the ethnic group distribution in both lockdown and post-lockdown of anxiety, depression, sleep disturbance, and substance use. A 2 -sided $P$-value $<0.05$ was considered significant. All statistical analyses were performed using SAS v9.4 (SAS Institute, Cary, NC).

\section{Results}

The final analytical sample included 189 patients $(90.4 \%$ female, mean age 52.4 years, SD 11.1); 39 BS patients were enrolled in the lockdown phase, while the majority $(n=150)$ were from post-lockdown. Patients' demographics were similar in lockdown and post-lockdown. About a half were NHW (51.2\% for lockdown and $46.9 \%$ for post-lockdown), and nearly a third were NHB $33.3 \%$ for lockdown and $29.3 \%$ for post-lockdown). The majority (54.5\%) were college graduates, and more than half of the sample $(52.1 \%)$ had an annual household income $>\$ 75,000$. Mean BMI for patients from lockdown and post-lockdown was $37.1 \mathrm{~kg} / \mathrm{m}^{2}$ (SD 7.7) and $36.8 \mathrm{~kg} / \mathrm{m}^{2}$ (SD 9.1), respectively. On average, patients from lockdown and post-lockdown had BS about 7 to 8 years ago, respectively; however, $40 \%$ of the sample had completed BS since 2015. Self-reported medical conditions were highly prevalent in both lockdown and post-lockdown and included high blood pressure (42.0\%), hyperlipidemia (21.3\%), sleep apnea $(26.6 \%)$, diabetes $(20.2 \%)$, asthma $(21.3 \%)$, heart disease $(20.2 \%)$, and active cancer treatment (3.2\%). A total of 3 post-lockdown patients $(2.0 \%)$ reported that they had tested positive for SARS-CoV-2, while more patients (9.0\%) reported having COVID-19 symptoms. Fewer $(78.0 \%)$ patients in post-lockdown chose to stay at home compared to those $(89.7 \%)$ in lockdown, while $71.4 \%$ reported only leaving their homes for necessities, followed by $43.6 \%$ who went outside for walks or exercise (Table 1).

The majority $(68.0 \%)$ of the sample reported that it was more difficult to achieve their weight loss goals during the pandemic, while $25.0 \%$ reported no impact. About half (48.6\%) reported a decreased amount of time for exercise, and $49.1 \%$ reported a decrease in intensity of exercise. Slightly more than a third $(35.6 \%)$ of the sample reported grocery shopping once a week, and another third $(31.1 \%)$ reported shopping 1-2 times a month. More than half of the sample reported an increase in stockpiling food. Well over half $(63.0 \%)$ reported that healthy eating was more challenging, and $64.8 \%$ reported stress eating. More than a half reported cooking more often $(57.6 \%)$, while less than one-third $(27.8 \%)$ reported baking more. Food insecurity was described by $7.2 \%$ of the sample. Over half $(58.4 \%)$ reported that their frequency of leaving their home did not change after the lockdown orders were lifted. None of these reported behavior changes were significantly different by lockdown/postlockdown (Table 2).

Table 2 also shows that patients from lockdown were significantly more likely to have sleep problems $(74.3 \%$ vs. $56.1 \%, P=.039)$ or feel anxious $(82.0 \%$ vs. $63.0 \%, P=.024)$ than those in post-lockdown. Conversely, significantly more patients reported substance use in post-lockdown than lockdown $(33.3 \%$ vs. $2.5 \%, P=.0001)$. A majority $(83.4 \%)$ of the sample reported depression, and it was similar in both lockdown/post-lockdown.

After controlling for key demographics, education, BMI, and COVID-19 infection, compared with lockdown patients, post-lockdown patients were significantly less likely to report difficulty falling asleep (adjusted odds ratio (aOR) 0.41, 95\% CI 0.17-0.97) and anxiety (aOR 0.37, 95\% CI 0.14-0.99). Strikingly, patients in post-lockdown were more than 20 times 
Table 1 MBS Patient

Demographic and Medical Information ( $\mathrm{n}=189)$, COVID19 and Obesity Study

\begin{tabular}{|c|c|c|c|}
\hline Variables & $\begin{array}{l}\text { Total } \\
(\mathrm{n}=189)\end{array}$ & $\begin{array}{l}\text { During lockdown } \\
(\mathrm{n}=39)\end{array}$ & $\begin{array}{l}\text { Post-lockdown } \\
(\mathrm{n}=150)\end{array}$ \\
\hline Male, n (\%) & $18(9.6)$ & $5(12.8)$ & $13(8.6)$ \\
\hline Age, mean (SD) & $52.4(11.1)$ & $50.28(10.4)$ & $53.02(11.2)$ \\
\hline \multicolumn{4}{|l|}{ Race, n (\%) } \\
\hline Non-Hispanic White & $89(49.8)$ & $20(51.2)$ & $69(46.9)$ \\
\hline Non-Hispanic Black & $57(30.6)$ & $13(33.3)$ & $44(29.3)$ \\
\hline Hispanic & $30(16.1)$ & $3(7.6)$ & $27(18.3)$ \\
\hline Other & $10(5.3)$ & $3(7.6)$ & $7(4.7)$ \\
\hline \multicolumn{4}{|l|}{ Education, $\mathrm{n}(\%)$} \\
\hline Some high school & $1(0.5)$ & $1(2.5)$ & $0(0)$ \\
\hline High school graduate & $17(9.0)$ & $3(7.6)$ & $14(9.3)$ \\
\hline Some college or technical school & $68(36.2)$ & $12(30.7)$ & $56(37.3)$ \\
\hline College graduate & $103(54.5)$ & $23(58.9)$ & $80(53.3)$ \\
\hline \multicolumn{4}{|l|}{ Annual household income, n (\%) } \\
\hline$<\$ 25,000$ & $17(9.0)$ & $1(2.5)$ & $16(10.7)$ \\
\hline$\$ 25,000-49,999$ & $31(16.8)$ & $7(17.9)$ & $24(12.0)$ \\
\hline$\$ 50,000-74,999$ & $42(22.3)$ & $6(15.3)$ & $36(24.1)$ \\
\hline$\geq 75,000$ & $98(52.1)$ & $25(64.1)$ & $73(48.9)$ \\
\hline BMI, mean (SD) & $36.8(8.8)$ & $37.1(7.3)$ & $36.8(9.1)$ \\
\hline Time since MBS, months (SD) & $97(86.1)$ & $90(98.2)$ & $99(82.7)$ \\
\hline \multicolumn{4}{|l|}{ Medical conditions, $\mathrm{n}(\%)$} \\
\hline Active cancer treatment & $6(3.2)$ & $0(0)$ & $6(4.0)$ \\
\hline Asthma/other pulmonary disease & $40(21.3)$ & $4(10.26)$ & $36(24.0)$ \\
\hline Diabetes & $38(20.2)$ & $2(5.1)$ & $36(24.0)$ \\
\hline Heart disease & $10(5.3)$ & $3(7.6)$ & $7(4.6)$ \\
\hline High blood pressure & $79(42.0)$ & $19(48.7)$ & $60(40.0)$ \\
\hline High cholesterol/hyperlipidemia & $40(21.3)$ & $5(12.8)$ & $35(23.3)$ \\
\hline Sleep apnea & $50(26.6)$ & $15(38.4)$ & $35(23.3)$ \\
\hline Test positive for COVID-19, n (\%) & $3(1.6)$ & $0(0)$ & $3(2.0)$ \\
\hline \multicolumn{4}{|l|}{ COVID-19 symptoms, n (\%) } \\
\hline Asymptomatic & $2(11.8)$ & $0(0)$ & $2(14.2)$ \\
\hline Very mild & $8(47.1)$ & $1(33.3)$ & $750.0)$ \\
\hline Moderate & $3(17.7)$ & $2(66.6)$ & $1(7.1)$ \\
\hline Severe & $4(23.5)$ & $0(0)$ & $4(28.5)$ \\
\hline Very severe & $0(0)$ & $0(0)$ & $0(0)$ \\
\hline Total & $17(9.0)$ & $3(7.6)$ & $14(9.4)$ \\
\hline Staying at home since COVID-19, n (\%) & $152(80.4)$ & $35(89.7)$ & $117(78.0)$ \\
\hline \multicolumn{4}{|l|}{ Level of quarantine, $\mathrm{n}(\%)$} \\
\hline Not going outside at all & $5(2.7)$ & $1(2.5)$ & $4(2.6)$ \\
\hline Going outside for walks or exercise & $82(43.6)$ & $21(53.8)$ & $61(40.6)$ \\
\hline $\begin{array}{l}\text { Going outside for necessities (food, } \\
\text { medications) }\end{array}$ & $135(71.4)$ & $32(82.0)$ & $103(68.6)$ \\
\hline Visiting close family/friends & $36(19.2)$ & $6(15.3)$ & $30(20.0)$ \\
\hline Going to work & $20(10.6)$ & $6(15.3)$ & $14(9.3)$ \\
\hline Attending religious services & $8(4.7)$ & $0(0)$ & $8(5.3)$ \\
\hline Attending parties/large social functions & $0(0)$ & $0(0)$ & $0(0)$ \\
\hline Going out as normal & $0(0)$ & $0(0)$ & $0(0)$ \\
\hline Lost job since COVID-19, n (\%) & $14(7.5)$ & $5(13.1)$ & $9(6.0)$ \\
\hline
\end{tabular}


Table 2 Change of weight-related behaviors and psychological factors post-COVID-19 lockdown orders by MBS, COVID-19 and obesity study phase

\begin{tabular}{|c|c|c|c|c|c|}
\hline & & \multicolumn{3}{|l|}{$\mathrm{N}(\%)$} & \multirow[b]{2}{*}{$P$-value* } \\
\hline & & Total $(\mathrm{n}=189)$ & $\begin{array}{l}\text { During lockdown } \\
(\mathrm{n}=39)\end{array}$ & $\begin{array}{l}\text { Post-lockdown } \\
(\mathrm{n}=150)\end{array}$ & \\
\hline \multirow[t]{3}{*}{ Weight loss goal } & Easier to achieve & $13(6.9)$ & $2(5.6)$ & $11(7.3)$ & \multirow[t]{3}{*}{0.868} \\
\hline & Not affect & $47(25.0)$ & $9(23.6)$ & $38(25.3)$ & \\
\hline & Harder to achieve & $128(68.0)$ & $27(71.0)$ & $101(67.3)$ & \\
\hline \multirow[t]{4}{*}{ Exercise time } & Decreased & $92(48.6)$ & $15(38.4)$ & $77(51.3)$ & \multirow[t]{4}{*}{0.428} \\
\hline & Unchanged & $39(20.6)$ & $8(20.5)$ & $31(20.6)$ & \\
\hline & Increased & $36(19.0)$ & $10(25.6)$ & $26(17.3)$ & \\
\hline & Do not exercise & $22(11.6)$ & $6(15.3)$ & $16(10.6)$ & \\
\hline \multirow[t]{3}{*}{ Exercise intensity } & Decreased & $82(49.1)$ & $15(45.5)$ & $67(50.0)$ & \multirow[t]{3}{*}{0.896} \\
\hline & Unchanged & $66(39.5)$ & $14(42.2)$ & $52(38.8)$ & \\
\hline & Increased & $19(11.3)$ & $4(12.1)$ & $15(11.1)$ & \\
\hline \multirow[t]{4}{*}{ Food shopping frequency } & Never/home delivery & $31(17.8)$ & $5(13.8)$ & $26(18.8)$ & \multirow[t]{4}{*}{0.911} \\
\hline & 1-2 times/month & $57(32.7)$ & $12(33.3)$ & $45(32.6)$ & \\
\hline & 1 time/week & $62(35.6)$ & $14(38.8)$ & $48(34.7)$ & \\
\hline & $\geq 2$ times/week & $24(13.7)$ & $5(13.8)$ & $19(13.7)$ & \\
\hline \multirow[t]{3}{*}{ Stockpile food } & Less & $5(2.7)$ & $1(2.7)$ & $4(2.7)$ & \multirow[t]{3}{*}{0.874} \\
\hline & Unchanged & $81(44.2)$ & $15(40.5)$ & $66(45.2)$ & \\
\hline & More & $97(53.0)$ & $21(56.7)$ & $76(52.0)$ & \\
\hline \multirow[t]{3}{*}{ Follow health diet plans } & Easier & $17(9.2)$ & $3(7.8)$ & $14(9.5)$ & \multirow[t]{3}{*}{0.509} \\
\hline & Unchanged & $51(27.7)$ & $8(21.0)$ & $43(29.4)$ & \\
\hline & More challenging & $116(63.0)$ & $27(71.0)$ & $89(60.9)$ & \\
\hline \multirow[t]{2}{*}{ Stress eat more } & Yes & $118(64.8)$ & $29(76.3)$ & $89(61.8)$ & \multirow[t]{2}{*}{0.095} \\
\hline & No & $64(35.1)$ & $9(23.6)$ & $55(38.1)$ & \\
\hline \multirow[t]{3}{*}{ Cooking activity } & Less & $24(13.0)$ & $4(10.5)$ & $20(13.7)$ & \multirow[t]{3}{*}{0.858} \\
\hline & Unchanged & $54(29.3)$ & $11(28.9)$ & $43(29.4)$ & \\
\hline & More & $106(57.6)$ & $23(60.5)$ & $83(56.8)$ & \\
\hline \multirow[t]{3}{*}{ Baking activity } & Less & $24(13.1)$ & $3(8.1)$ & $21(14.3)$ & \multirow[t]{3}{*}{0.557} \\
\hline & Unchanged & $108(59.0)$ & $24(64.8)$ & $84(57.5)$ & \\
\hline & More & $51(27.8)$ & $10(27.0)$ & $41(28.0)$ & \\
\hline \multirow[t]{3}{*}{ Cannot afford to eat balanced meals } & Often & $13(7.2)$ & $2(5.4)$ & $11(7.6)$ & \multirow[t]{3}{*}{0.528} \\
\hline & Sometimes & $26(14.4)$ & $3(8.1)$ & $23(16.0)$ & \\
\hline & Never & $140(77.7)$ & $32(86.4)$ & $108(75.5)$ & \\
\hline \multirow{3}{*}{$\begin{array}{l}\text { Going out frequency since the } \\
\text { stay-at-home orders have been lifted }\end{array}$} & Less & $43(27.9)$ & $4(66.6)$ & $39(26.3)$ & \multirow[t]{3}{*}{0.087} \\
\hline & No difference & $90(58.4)$ & $2(33.3)$ & $88(59.4)$ & \\
\hline & More & $21(13.6)$ & $0(0.0)$ & $21(14.1)$ & \\
\hline Difficulty falling asleep & Yes & $111(60.0)$ & $29(74.3)$ & $82(56.1)$ & 0.039 \\
\hline & No & $74(40.0)$ & $10(25.6)$ & $64(43.8)$ & \\
\hline Anxiety & Yes & $124(67.0)$ & $32(82.0)$ & $92(63.0)$ & 0.024 \\
\hline & No & $61(32.9)$ & $7(17.9)$ & $54(36.9)$ & \\
\hline Substance abuse & Yes & $51(26.9)$ & $1(2.5)$ & $50(33.3)$ & 0.0001 \\
\hline & No & $138(73.02)$ & $38(97.4)$ & $100(66.6)$ & \\
\hline Depression & Yes & $151(83.4)$ & $35(92.1)$ & $116(81.1)$ & 0.105 \\
\hline & No & $30(16.5)$ & $3(7.8)$ & $27(18.8)$ & \\
\hline
\end{tabular}

*Chi-square test

more likely to report substance use compared those in lockdown (aOR 20.56, 95\% CI 2.66-158.4) (Table 3).

Figure 1 demonstrated the percentage of patients with depression, sleep difficulty, substance use, and anxiety by ethnic groups in lockdown and post-lockdown. The distribution of ethnic groups was very similar in these variables of interests. For example, in post-lockdown, the majority who reported depression (36.4\%), difficulty falling asleep $(38.5 \%)$, substance use (52\%), and anxiety (39.3\%) were NHW, followed by NHB, Hispanics, and others. Interestingly, only NHB (2\%) 
Table 3 Crude and adjusted odds ratio for MBS in phase 2 by weight-related behaviors and psychological factors

\begin{tabular}{|c|c|c|c|c|}
\hline Variables & Crude odd $(95 \% \mathrm{CI})^{\mathrm{a}}$ & $P$-value ${ }^{\mathrm{a}}$ & Adjusted odds $(95 \% \mathrm{CI})^{\mathrm{b}}$ & $P$-value ${ }^{\mathrm{b}}$ \\
\hline \multicolumn{5}{|l|}{ Stockpile food } \\
\hline Less or unchanged & $1.0(\mathrm{ref})$ & - & 1.0 (ref) & - \\
\hline More & $0.79(0.38-1.62)$ & 0.529 & $0.78(0.36-1.69)$ & 0.525 \\
\hline \multicolumn{5}{|c|}{ Follow healthy eating pattern } \\
\hline Easier or unchanged & 1.0 (ref) & - & 1.0 (ref) & - \\
\hline More challenging & $0.64(0.29-1.38)$ & 0.258 & $0.62(0.27-1.40)$ & 0.251 \\
\hline \multicolumn{5}{|l|}{ Stress eat more } \\
\hline Yes & $0.50(0.22-1.14)$ & 0.099 & $0.48(0.20-1.14)$ & 0.096 \\
\hline No & 1.0 (ref) & - & 1.0 (ref) & - \\
\hline \multicolumn{5}{|l|}{ Cooking activity } \\
\hline Less & $1.27(0.36-4.51)$ & 0.625 & $1.25(0.33-4.61)$ & 0.740 \\
\hline Unchanged & 1.0 (ref) & - & 1.0 (ref) & - \\
\hline More & $0.92(0.41-2.07)$ & 0.610 & $1.04(0.44-2.45)$ & 0.870 \\
\hline \multicolumn{5}{|l|}{ Baking activity } \\
\hline Less & $2.00(0.54-7.28)$ & 0.346 & $1.41(0.35-5.60)$ & 0.663 \\
\hline Unchanged & 1.0 (ref) & - & 1.0 (ref) & - \\
\hline More & $1.17(0.51-2.67)$ & 0.696 & $1.10(0.44-2.75)$ & 0.878 \\
\hline \multicolumn{5}{|c|}{ Going out frequency since the stay-at-home orders have been lifted } \\
\hline Less often & $0.22(0.03-1.26)$ & 0.940 & $0.29(0.04-2.03)$ & 0.958 \\
\hline No difference & 1.0 (ref) & - & 1.0 (ref) & - \\
\hline More often & $>999(<0.001->999)$ & 0.950 & $>999(<0.001->999)$ & 0.964 \\
\hline \multicolumn{5}{|l|}{ Weight loss goal } \\
\hline Easier to achieve & $1.30(0.24-6.93)$ & 0.684 & $1.23(0.20-7.42)$ & 0.706 \\
\hline Unchanged & 1.0 (ref) & - & 1.0 (ref) & - \\
\hline More difficult to achieve & $0.88(0.38-2.05)$ & 0.596 & $0.79(0.32-1.95)$ & 0.520 \\
\hline \multicolumn{5}{|l|}{ Exercise time } \\
\hline Decreased & $1.32(0.51-3.43)$ & 0.146 & $1.59(0.55-4.5)$ & 0.063 \\
\hline No difference & 1.0 (ref) & - & 1.0 (ref) & - \\
\hline Increased & $0.67(0.23-1.94)$ & 0.398 & $0.83(0.26-2.66)$ & 0.823 \\
\hline Do not exercise & $0.68(0.20-2.32)$ & 0.520 & $0.50(0.13-1.84)$ & 0.163 \\
\hline \multicolumn{5}{|l|}{ Exercise intensity } \\
\hline Decreased & $1.20(0.54-2.71)$ & 0.674 & $1.51(0.62-3.68)$ & 0.480 \\
\hline Unchanged & 1.0 (ref) & - & 1.0 (ref) & - \\
\hline Increased & $1.01(0.28-3.52)$ & 0.890 & $1.19(0.31-4.53)$ & 0.966 \\
\hline \multicolumn{5}{|l|}{ Difficulty falling asleep } \\
\hline Yes & $0.44(0.20-0.97)$ & 0.042 & $0.41(0.17-0.97)$ & 0.042 \\
\hline No & 1.0 (ref) & - & 1.0 (ref) & - \\
\hline \multicolumn{5}{|l|}{ Anxiety } \\
\hline Yes & $0.37(0.15-0.90)$ & 0.028 & $0.37(0.14-0.99)$ & 0.048 \\
\hline No & 1.0 (ref) & - & 1.0 (ref) & - \\
\hline \multicolumn{5}{|l|}{ Substance abuse } \\
\hline Yes & $18.9(2.5-142.4)$ & 0.004 & $20.56(2.66-158.4)$ & 0.003 \\
\hline No & 1.0 (ref) & - & 1.0 (ref) & - \\
\hline \multicolumn{5}{|l|}{ Depression } \\
\hline Yes & $0.36(0.10-1.28)$ & 0.117 & $0.42(0.11-1.53)$ & 0.1901 \\
\hline No & 1.0 (ref) & - & 1.0 (ref) & - \\
\hline
\end{tabular}

${ }^{\text {a }}$ Crude logistic regression

${ }^{\mathrm{b}}$ Also adjusted for age, gender, race, education, BMI, COVID-19 infection 


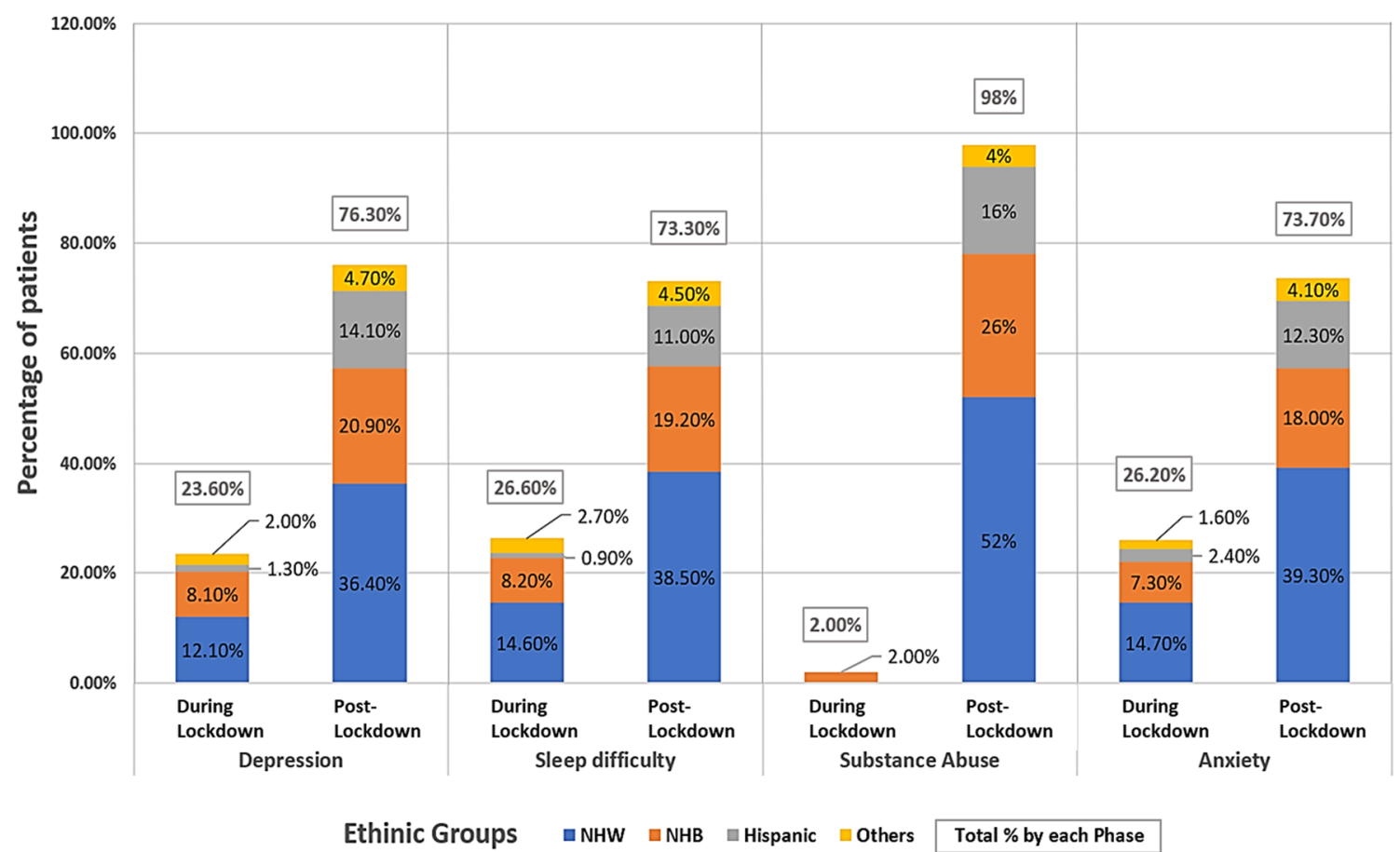

Fig. 1 Ethnic group distribution of depression, anxiety, sleep disturbances, and substance use among bariatric surgery study participants during lockdown and post-lockdown orders

reported substance use in lockdown, while $26 \%$ of NHB reported substance use in post-lockdown.

\section{Discussion}

Analysis showed that substance use significantly increased over the course of the pandemic in the context of persistently high levels of self-reported insomnia ( $>55 \%)$, anxiety ( $>60 \%)$, and depression $(>80 \%)$ in both lockdown and several months after lockdown orders were lifted. Ethnic group distribution in anxiety, depression, sleep disturbance, and substance use were similar. There is likely a bidirectional relationship with these mental health challenges and other changes in health behaviors and circumstances including decreased physical activity, difficulty with healthy eating patterns, stress eating, food insecurity, and job loss. These findings have major implications for BS care teams as well as other healthcare professionals who have BS patients in their care as they identify and manage the psychosocial effects of the pandemic in this vulnerable population. These findings also suggest the need for rapid implementation and dissemination of telehealth-delivered psychosocial care and implementation science research [34].

While the analysis did not find statistical differences in many of the weight-related behaviors between lockdown and post-lockdown, this high overall prevalence of selfreported challenges is striking. For example, over $2 / 3$ of the sample reported difficulty in achieving weight loss goals, which was likely driven by around half the population reporting decreased exercise, increased stockpiling of food, and difficulty with healthy dietary patterns. In addition, there are suggestions of superimposed financial stress of the pandemic as over $20 \%$ of respondents reported at least some difficulty affording healthy meals and over $7 \%$ became unemployed during the pandemic.

High levels of self-reported anxiety, depression, and insomnia have been documented in people with obesity during the pandemic [29]. In our cohort, it is concerning that these psychological stresses appear to be occurring in conjunction with coping mechanisms such as stress eating and substance use in people with a history of BS. The relationship between chronic stress, mental health disorders, and substance use is well documented in the literature $[2,56]$, in addition to the bidirectional relationship between stress and obesity [3, 57].

To our knowledge, this is the first report of substance use behaviors among ethnically diverse BS patients for an extended period through the COVID-19 pandemic, that is, for months beyond the initial hard lockdown phases that occurred worldwide. Most published quantitative studies that have focused on the psychosocial impact of the epidemic on BS patients collected data during the first wave only $[36,40]$, had no information on ethnic distribution of the sample $[4,37,40$, $58]$, or were majority non-Hispanic White participants [36, $60]$, and none collected data on substance use behaviors. Two international qualitative studies with sample sizes $<25$ either were majority non-Hispanic White $[6,61]$ or did not report ethnicity $[7,62]$ and neither reported on substance use behaviors in BS patients. A history of BS is associated with 
increased substance, and this is thought to be due to a variety of psychosocial and physiological factors [8, 9, 63-66]. In the current study, education, income, and ethnicity do not appear to be associated with or protective against these increases in mental health stresses and behaviors for post-BS patients. This suggests the need for broad outreach and education initiatives for BS patients to ensure that their mental health needs are being met during the pandemic in order to mitigate the impact on health behaviors that could be deleterious to body weight, metabolic outcomes, and overall wellbeing.

There are several limitations to this study that should be mentioned. First, this was a sample of convenience which can produce selection bias. Respondents were primarily college-educated NHW women with an average age of 51 years and an annual income of $\geq \$ 75,000$. This study may not be generalizable to a clinic that treats a different demographic of people, a healthy weight population, or non-BS patients. It may also not be generalizable to other populations and as a result may not accurately assess the burden of COVID-19 on obesity-related health and behaviors in lower socioeconomic status who are disproportionately more affected by obesity and COVID-19. Participants were established weight management patients with secured health insurance, which is not representative of the average American challenged with obesity. Another limitation is that behavioral changes were based on the patient's own perception at the time of the survey rather than on quantifying these behaviors (such as exercise time decreased from 120 to $60 \mathrm{~min} /$ week). Furthermore, we infer that an increase in behaviors that favor weight gain during COVID-19 would lead to worsening obesity but are not able to present longitudinal causal effect data on changes in body weight due to the study design. Strengths of the study include the capture of important information to inform comprehensive, future healthcare for BS patients to optimize health behaviors and outcomes while mitigating risks.

Data from this study support the creation of programs for BS patients to screen for mental health and health behaviors that could undermine weight management and overall health in this vulnerable population as the world recovers from the COVID-19 pandemic. Healthcare access should be optimized for BS patients through novel strategies, including telehealth and mental health outreach, for the duration of the pandemic and beyond.

In conclusion, the COVID-19 pandemic is having a durable negative impact on the health behaviors and mental health of people with a history of BS. This vulnerable group reports high levels of anxiety and depression, which have been reported in tandem with maladaptive coping mechanisms such as substance use and stress eating. These behaviors may undermine post-BS weight management, metabolic outcomes, and overall health. Appropriate screening and intervention programs must be implemented for this at-risk population.

Supplementary Information The online version contains supplementary material available at https://doi.org/10.1007/s11695-021-05488-6.

Funding This study was funded by the National Institute of Minority Health and Health Disparities (Grant \#s R01MD011686 and R01MD011686-S1).

\section{Declarations}

Ethics Approval All procedures performed in studies involving human participants were in accordance with the ethical standards of the University of Texas Health Science Center research committee and with the 1964 Helsinki declaration and its later amendments or comparable ethical standards.

Informed Consent Informed consent was obtained from all individual participants included in the study.

Conflict of Interest The authors declare no competing interests.

\section{References}

1. Callaway E. Time to use the p-word? Coronavirus enters dangerous new phase. Nature. 2020; https://doi.org/10.1038/d41586-02000551-1.

2. Lighter J, Phillips M, Hochman S, et al. Obesity in patients younger than 60 years is a risk factor for COVID-19 hospital admission. Clin Infect Dis. 2020;71:896-7. https://doi.org/10.1093/cid/ciaa415.

3. Simonnet A, Chetboun M, Poissy J, et al. High prevalence of obesity in severe acute respiratory syndrome coronavirus-2 (SARSCoV-2) requiring invasive mechanical ventilation. Obesity. 2020;28:1195-9. https://doi.org/10.1002/oby.22831.

4. Garg S, Kim L, Whitaker M, et al. Hospitalization rates and characteristics of patients hospitalized with. Morb Mortal Wkly Report, US Dep Heal Hum Serv Dis Control Prev. 2020;69(15):458-464.

5. Petrilli C, Jones S, Yang J, et al. Factors associated with hospitalization and critical illness among 5279 patients with COVID-19 disease in New York City. BMJ. 2020; https://doi.org/10.1136/ bmj.m1966.

6. Kim T, Roslin M, Wang JJ, et al. Body mass index as a risk factor for clinical outcomes in patients hospitalized with COVID-19 in New York. Obesity. 2020;29:279-84. https://doi.org/10.1002/oby. 23076.

7. Dietz W, Santos-Burgoa C. Obesity and its implications for COVID-19 mortality. Obesity. 2020;28:1005. https://doi.org/10. 1002/oby.22818.

8. Ong SWX, Young BE, Leo YS, et al. Association of higher body mass index with severe coronavirus disease 2019 (COVID-19) in younger patients. Clin Infect Dis. 2020;71:2300-2. https://doi.org/ 10.1093/cid/ciaa548.

9. Richardson S, Hirsch JS, Narasimhan M, et al. Presenting characteristics, comorbidities, and outcomes among 5700 patients hospitalized with COVID-19 in the New York City Area. JAMA - J Am 
Med Assoc. 2020;323:2052-9. https://doi.org/10.1001/jama.2020. 6775.

10. Abbatini F, Capoccia D, Casella G, et al. Long-term remission of type 2 diabetes in morbidly obese patients after sleeve gastrectomy. Surg Obes Relat Dis. 2013;9:498-502. https://doi.org/10.1016/j. soard.2012.09.003.

11. Angrisani L, Santonicola A, Iovino P, et al. Bariatric Surgery Worldwide 2013. Obes Surg. 2015;25:1822-32. https://doi.org/ 10.1007/s11695-015-1657-z.

12. Buchwald H, Avidor Y, Braunwald E, et al. Bariatric surgery: a systematic review and meta-analysis. J Am Med Assoc. 2004;292: 1724-37. https://doi.org/10.1001/jama.292.14.1724.

13. Carlsson LMS, Peltonen M, Ahlin S, et al. Bariatric surgery and prevention of type 2 diabetes in Swedish obese subjects. N Engl J Med. 2012;367:695-704. https://doi.org/10.1056/nejmoa1112082.

14. Chang S-H, Stoll CRT, Song J, et al. The effectiveness and risks of bariatric surgery. JAMA Surg. 2014;149:275-87. https://doi.org/ 10.1001/jamasurg.2013.3654.

15. Rubino F, Nathan DM, Eckel RH, et al. Metabolic surgery in the treatment algorithm for type 2 diabetes: a joint statement by international diabetes organizations. Diabetes Care. 2016;39:861-77. https://doi.org/10.2337/dc16-0236.

16. Uccelli M, Cesana GC, De Carli SM, et al. COVID-19 and obesity: is bariatric surgery protective? Retrospective analysis on 2145 patients undergone bariatric-metabolic surgery from high volume center in Italy (Lombardy). Obes Surg. 2020;31:942-8. https://doi.org/ 10.1007/s11695-020-05085-z.

17. Aminian A, Fathalizadeh $\mathrm{A}, \mathrm{Tu} \mathrm{C}$, et al. Association of prior metabolic and bariatric surgery with severity of coronavirus disease 2019 (COVID-19) in patients with obesity. Surg Obes Relat Dis. 2020;17:208-14. https://doi.org/10.1016/j.soard.2020.10.026.

18. Iannelli A, Bouam S, Schneck AS, et al. The impact of previous history of bariatric surgery on outcome of COVID-19. A Nationwide Medico-Administrative French Study. Obes Surg. 2020; https://doi.org/10.1007/s11695-020-05120-z.

19. Rubino F, Cohen RV, Mingrone G, et al. Bariatric and metabolic surgery during and after the COVID-19 pandemic: DSS recommendations for management of surgical candidates and postoperative patients and prioritisation of access to surgery. Lancet Diabetes Endocrinol. 2020;8:640-8. https://doi.org/10.1016/S22138587(20)30157-1.

20. Almandoz JP, Xie L, Schellinger JN, et al. Impact of COVID -19 stay-at-home orders on weight - related behaviours among patients with obesity. Clin Obes. 2020;10:e12386. https://doi.org/10.1111/ cob. 12386

21. Nicoletti CF, Esteves GP, Genario R, et al. Nutritional inadequacies among post-bariatric patients during COVID-19 quarantine in Sao Paulo, Brazil. Obes Surg. 2020;31:2330-4. https://doi.org/10.1007/ s11695-020-05107-w.

22. Chiesa V, Antony G, Wismar M, et al. COVID-19 pandemic: health impact of staying at home, social distancing and 'lockdown' measures-a systematic review of systematic reviews. J Public Health (Oxf). 2021:fdab102. https://doi.org/10.1093/pubmed/ fdab102. Epub ahead of print

23. Phiri P, Ramakrishnan R, Rathod S, et al. An evaluation of the mental health impact of SARS-CoV-2 on patients, general public and healthcare professionals: a systematic review and meta-analysis. EClinicalMedicine. 2021;34:100806. https://doi.org/10.1016/j. eclinm.2021.100806. Epub 2021 Apr 6

24. Xiong J, Lipsitz O, Nasri F, et al. Impact of COVID-19 pandemic on mental health in the general population: a systematic review. J Affect Disord. 2020;277:55-64.

25. Sukut O, Ayhan Balik CH. The impact of COVID-19 pandemic on people with severe mental illness. Perspect Psychiatr Care. 2020; https://doi.org/10.1111/ppc.12618. Epub ahead of print
26. Muruganandam P, Neelamegam S, Menon V, et al. COVID-19 and severe mental illness: impact on patients and its relation with their awareness about COVID-19. Psychiatry Res. 2020;291:113265.

27. Hamada K, Fan X. The impact of COVID-19 on individuals living with serious mental illness. Schizophr Res. 2020;222:3-5. https:// doi.org/10.1016/j.schres.2020.05.054. Epub 2020 May 27

28. Conason A, Teixeira J, Hsu CH, et al. Substance use following bariatric weight loss surgery. JAMA Surg. 2013;148:145-50. https://doi.org/10.1001/2013.jamasurg.265.

29. King WC, Chen JY, Mitchell JE, et al. Prevalence of alcohol use disorders before and after bariatric surgery. JAMA - J Am Med Assoc. 2012;307:2516-25. https://doi.org/10.1001/jama.2012. 6147.

30. Suzuki J, Haimovici F, Chang G. Alcohol use disorders after bariatric surgery. Obes Surg. 2012;22:201-7. https://doi.org/10.1007/ s11695-010-0346-1.

31. Mühlhans B, Horbach T, de Zwaan M. Psychiatric disorders in bariatric surgery candidates: a review of the literature and results of a German prebariatric surgery sample. Gen Hosp Psychiatry. 2009;31(5):414-21. https://doi.org/10.1016/j.genhosppsych.2009. 05.004. Epub 2009 Jul 21

32. Mitchell JE, Selzer F, Kalarchian MA, et al. Psychopathology before surgery in the longitudinal assessment of bariatric surgery-3 (LABS-3) psychosocial study. Surg Obes Relat Dis. 2012;8(5): 533-41. https://doi.org/10.1016/j.soard.2012.07.001. Epub 2012 Jul 14. PMID: 22920965; PMCID: PMC3584713

33. Sockalingam S, Hawa R, Wnuk S, et al. Weight loss following Roux-en-Y gastric bypass surgery: a systematic review of psychosocial predictors. Curr Psych Rev. 2011;7:226-33.

34. Sockalingam S, Leung SE, Cassin SE. The impact of coronavirus disease 2019 on bariatric surgery: redefining psychosocial care. Obesity. 2020;28:1010-2. https://doi.org/10.1002/oby.22836.

35. Wang $\mathrm{C}$, Pan $\mathrm{R}$, Wan $\mathrm{X}$, et al. Immediate psychological responses and associated factors during the initial stage of the 2019 coronavirus disease (COVID-19) epidemic among the general population in China. Int J Environ Res Public Health. 2020;17 https://doi.org/10. 3390/ijerph17051729.

36. Athanasiadis DI, Hernandez E, Hilgendorf W, et al. How are bariatric patients coping during the coronavirus disease 2019 (COVID19) pandemic? Analysis of factors known to cause weight regain among postoperative bariatric patients. Surg Obes Relat Dis. 2020: S1550-7289(20)30682-1. https://doi.org/10.1016/j.soard.2020.11. 021. Epub ahead of print. PMID: 33390351; PMCID: PMC7699156

37. Walędziak M, Różańska-Walędziak A, Pędziwiatr M, et al. Bariatric surgery during COVID-19 pandemic from patients' point of view-the results of a national survey. J Clin Med. 2020;9(6): 1697. https://doi.org/10.3390/jcm9061697. PMID: 32498298; PMCID: PMC7356361

38. Pinto SL, Juvanhol LL, Bressan J. Increase in Protein Intake After 3 Months of RYGB Is an independent predictor for the remission of obesity in the first year of surgery. Obes Surg. 2019 Dec;29(12): 3780-5.

39. Nicoletti CF, Esteves GP, Genario R, et al. Nutritional inadequacies among post-bariatric patients during COVID-19 quarantine in Sao Paulo, Brazil. Obes Surg. 2020:1-5. https://doi.org/10.1007/ s11695-020-05107-w. Epub ahead of print. PMID: 33231819; PMCID: PMC7683868

40. Sisto A, Vicinanza F, Tuccinardi D, et al. The psychological impact of COVID-19 pandemic on patients included in a bariatric surgery program. Eat Weight Disord. 2020:1-11. https://doi.org/10.1007/ s40519-020-00988-3. Epub ahead of print. PMID: 32857287; PMCID: PMC7453189

41. Boschuetz N, Cheng S, Mei L, et al. Changes in alcohol use patterns in the United States During COVID-19 Pandemic. WMJ. 2020; 
42. Robinson E, Gillespie S, Jones A. Weight-related lifestyle behaviours and the COVID-19 crisis: an online survey study of UK adults during social lockdown. Obes Sci Pract. 2020;6:735-40. https://doi. org/10.1002/osp4.442.

43. Pollard MS, Tucker JS, Green HD. Changes in adult alcohol use and consequences during the COVID-19 pandemic in the US. JAMA Netw Open. 2020;3:e2022942. https://doi.org/10.1001/ jamanetworkopen.2020.22942.

44. Rehm J, Kilian C, Ferreira-Borges C, et al. Alcohol use in times of the COVID 19: implications for monitoring and policy. Drug Alcohol Rev. 2020;39:301-4. https://doi.org/10.1111/dar.13074.

45. Grossman ER, Benjamin-Neelon SE, Sonnenschein S. Alcohol consumption during the covid-19 pandemic: a cross-sectional survey of us adults. Int J Environ Res Public Health. 2020;17(24):110. https://doi.org/10.3390/ijerph17249189.

46. Harris PA, Taylor R, Thielke R, et al. Research electronic data capture (REDCap) - a metadata-driven methodology and workflow process for providing translational research informatics support. $\mathrm{J}$ Biomed Inform. 2009 Apr;42(2):377-81.

47. Harris PA, Taylor R, Minor BL, et al. REDCap Consortium, The REDCap consortium: building an international community of software partners. J Biomed Inform. 2019;95:103208. https://doi.org/ 10.1016/j.jbi.2019.103208.

48. Census Reporter. https://censusreporter.org/profiles/ 31000US19100-dallas-fort-worth-arlington-tx-metro-area/ Accessed April 16, 2021.

49. USA Facts. Texas coronavirus cases and deaths. https://usafacts. org/visualizations/coronavirus-covid-19-spread-map/state/texas Accessed April 16, 2021.

50. PhenX toolkit. https://www.phenxtoolkit.org/ Accessed January 10,2020

51. Centers for Disease Control and Prevention (CDC). Behavioral Risk Factor Surveillance System Survey Questionnaire. Atlanta, Georgia: U.S. Department of Health and Human Services, Centers for Disease Control and Prevention; 2019.

52. United States Department of Agriculture (USDA). U.S. Household Food Security Survey Module: Six-Item Short Form. Washington, DC: U.S. Department of Agriculture, Economic Research Service, 2012. https://www.ers.usda.gov/media/8279/ad2012.pdf

53. Rush AJ, Trivedi MH, Ibrahim HM, et al. The 16-item Quick Inventory of Depressive Symptomatology (QIDS), clinician rating (QIDS-C), and self-report (QIDS-SR): a psychometric evaluation in patients with chronic major depression. Biol Psychiatry. 2003;54(5):573-83. https://doi.org/10.1016/S0006-3223(02) 01866-8.

54. Braund TA, Palmer DM, Williams LM, et al. Dimensions of anxiety in major depressive disorder and their use in predicting antidepressant treatment outcome: an iSPOT-D report. Psychol Med. $2020 ; 50(6): 1032-42$. https://doi.org/10.1017/ S0033291719000941. Epub 2019 Apr 26

55. National Institute on Alcohol and Alcoholism. National Epidemiologic Survey on Alcohol and Related Conditions-III
(NESARC-III). https://www.niaaa.nih.gov/research/nesarc-iii Accessed November 2, 2020.

56. Brady KT, Sinha R. Co-occurring mental and substance use disorders: the neurobiological effects of chronic stress. Am J Psychiatry. 2005;162(8):1483-93.

57. Van der Valk ES, Savas M, van Rossum EFC. Stress and obesity: are there more susceptible individuals? Curr Obes Rep. 2018;7: 193-203.

58. Conceição E, de Lourdes M, Ramalho S, et al. Eating behaviors and weight outcomes in bariatric surgery patients amidst COVID-19. Surg Obes Relat Dis. 2021:S1550-7289(21)00108-8. https://doi. org/10.1016/j.soard.2021.02.025. Epub ahead of print

59. Brown A, Flint SW, Kalea AZ, et al. Negative impact of the first COVID-19 lockdown upon health-related behaviours and psychological wellbeing in people living with severe and complex obesity in the UK. EClinicalMedicine. 2021:100796. https://doi.org/10. 1016/j.eclinm.2021.100796. Epub ahead of print

60. Petrilli C, Jones S, Yang J, et al. Factors associated with hospitalization and critical illness among 4103 patients with COVID-19 disease in New York City. BMJ. 2020; https://doi.org/10.1101/ 2020.04.08.20057794.

61. Youssef A, Cassin SE, Wnuk S, et al. The impact of COVID-19 pandemic on bariatric patients' self-management post-surgery. Appetite. 2021;162:105166. https://doi.org/10.1016/j.appet.2021. 105166. Epub ahead of print

62. Félix S, de Lourdes M, Ribeiro I, et al. A preliminary study on the psychosocial impact of COVID-19 lockdown in post-bariatric surgery women: the importance of eating behavior, health care access, and social support. Curr Psychol. 2021:1-7. https://doi.org/10. 1007/s12144-021-01529-6. Epub ahead of print

63. Li L, Wu LT. Substance use after bariatric surgery: A review. J Psychiatr Res. 2016;76:16-29. https://doi.org/10.1016/j. jpsychires.2016.01.009. Epub 2016 Jan 22

64. Kanji S, Wong E, Akioyamen L, et al. Exploring pre-surgery and post-surgery substance use disorder and alcohol use disorder in bariatric surgery: a qualitative scoping review. Int J Obes (Lond). 2019;43(9):1659-74. https://doi.org/10.1038/s41366-019-0397-x. Epub 2019 Jun 18. Erratum in: Int J Obes (Lond). 2019 Nov; 43(11):2348

65. King WC, Chen JY, Courcoulas AP, et al. Alcohol and other substance use after bariatric surgery: prospective evidence from a U.S. multicenter cohort study. Surg Obes Relat Dis. 2017;13(8):1392402.

66. Hales CM, Fryar CD, Carroll MD, et al. Trends in obesity and severe obesity prevalence in us youth and adults by sex and age, 2007-2008 to 2015-2016. JAMA - J Am Med Assoc. 2018;319(16):1723-5. https://doi.org/10.1001/jama.2018.3060.

Publisher's Note Springer Nature remains neutral with regard to jurisdictional claims in published maps and institutional affiliations. 